Cumhuriyet University

Journal of Economics and Administrative Sciences

E-ISSN: 2687-4032

2022, 23(1), pp.167-182.

Doi: 10.37880/cumuiibf.1000006

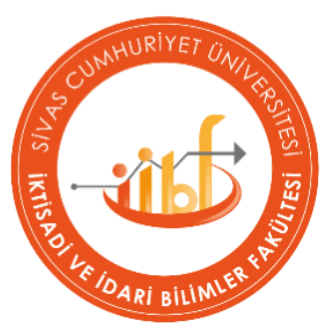

\title{
INVESTIGATION OF THE EFFECT OF EARLY COVID-19 PANDEMIC ON VOLATILITY IN EUROPEAN STOCK MARKETS
}

\author{
Bülent YILDIZ1 \\ Mehmet Metin DAM²
}

\begin{abstract}
In this study, it is aimed to reveal the short-term relationship between the volatility in European stock markets and the pandemic in the early period of the COVID-19 pandemic. In this context, the effect of the number of deaths and cases caused by the early period COVID-19 pandemic on the volatility in the European stock markets was tested by panel data analysis method. The study is important in the short term in terms of measuring the reaction of the markets to COVID-19 and sharing the results and contributing to the preparation of the markets for possible similar crisis periods. Turkey was included in the analysis, along with 15 European countries (England, Germany, Switzerland, Sweden, Italy, Ireland, Belgium, Norway, Austria, Denmark, Netherlands, France, Spain, Iceland, Portugal) with the highest number of cases and deaths by population for the period of the study. While investigating the effect of the pandemic on the volatility in the stock market indices of countries (DAX, ATX, BEL20, FTSE100, OMXC20, AEX, CAC40, FTSE MIB, IBEX35, ISEQ, SMI, OMXIPI, BIST100), daily data for the period 17.02.2020 24.04.2020 were used. Case increase rate, death increase rate and volatility were used as variables and two models were estimated. EViews 12 and Stata 15 econometric analysis programs were used in the analysis. Codes were used for variance and autocorrelation (model selection and validation tests). The expectation, in which the panel unit Root Test, the Breush - Pagan Lagrange Multiplier (LM) test, the Hausman endogeneity test, and the two-way random effects model estimate, is that increases in the number of cases and deaths will negatively affect stock market volatility. The panel data analysis was estimated with a two-way random effect model, and it is observed that the results obtained in both models are positive and statistically significant. That is, volatility increases by $0.01 \%$ when the case increase rate increases by $1 \%$, while it increases by $0.04 \%$ when the death rate increases by $1 \%$.
\end{abstract}

Article History:

Date submitted:

23 September 2021

Date accepted:

4 December 2021

\section{Jel Codes:}

C23, G01, G15

\section{Keywords:}

COVID-19 Pandemic, Stock Market Index, Volatility

Suggested Citation: Y1ld1z, B. \& Dam, M. M. (2022). Investigation of the Effect of Early Covid-19 Pandemic on Volatility in European Stock Markets. Cumhuriyet University Journal of Economics and Administrative Sciences, 23(1), 167-182.

${ }^{1}$ Asst. Prof. Dr., Aydın Adnan Menderes University, Faculty of Economics and Administrative Sciences, Department of International Trade and Finance, bulent.yildiz@ adu.edu.tr, ORCID ID: 0000-0001-6358-8620.

2 Assoc. Dr., Aydin Adnan Menderes University, Faculty of Economics and Administrative Sciences, Department of International Trade and Finance, metindam@adu.edu.tr, ORCID ID: 0000-0003-3980-7832 


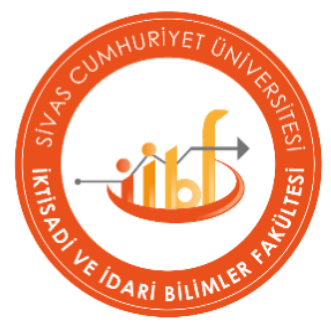

\section{ERKEN DÖNEM COVID-19 PANDEMISININ AVRUPA BORSALARINDAKİ VOLATILITEYE ETKISIININ ARAŞTIRILMASI}

\section{Bülent YILDIZ ${ }^{1}$ \\ Mehmet Metin DAM ${ }^{2}$ \\ $\ddot{O} z$}

Bu çalışmada, COVID-19 pandemisinin erken döneminde, Avrupa borsalarında yaşanan dalgalanmanın pandemi ile ilişkisinin kısa dönem için ortaya konulması amaçlanmıştır. Bu kapsamda, erken dönem COVID-19 pandemisi nedeniyle ortaya çıkan ölüm ve vaka sayılarının Avrupa borsalarındaki volatiliteye etkisi panel veri analizi yöntemiyle sınanmıştır. Çalışma kısa vadede, piyasaların COVID-19'a verdiği tepkinin ölçülerek sonuçlarının paylaşılması ve muhtemel benzer kriz dönemleri için piyasaların daha hazır hale gelmesine katkı yapması bakımından önemlidir. Analize, çalışmanın yapıldığ d dönem için vaka ve ölüm sayllarının nüfusa göre en yüksek olduğu 15 Avrupa ülkesi (İngiltere, Almanya, Ísviçre, İsveç, Italya, Irlanda, Belçika, Norveç, Avusturya, Danimarka, Hollanda, Fransa, İspanya, İzlanda, Portekiz) ile birlikte Türkiye de dahil edilmiştir. Çalışmada pandeminin ülkelerin borsa endekslerindeki (DAX, ATX, BEL20, FTSE100, OMXC20, AEX, CAC40, FTSE MIB, IBEX35, ISEQ, SMI, OMXIPI, BIST100) volatiliteye etkisi araştırllırken, 17.02.2020 - 24.04.2020 dönemine ait günlük veriler kullanılmıştır. Değişken olarak vaka artış hızı, ölüm artış hızı ve volatilite kullanılmış olup iki model tahmin edilmiştir. Analizlerde EViews 12 ve Stata 15 ekonometrik analiz programları kullanılmıştır. Değişen varyans ve otokorelasyon (model seçimi ve doğrulama testleri) için ise kodlar kullanılmıştır. Panel Birim Kök Testi, BreushPagan Lagrange Multiplier (LM) Testi, Hausman İçsellik Testi ve İki Yönlü Rassal Etkiler Model tahmininin yapıldı̆̆ bu çalışmadaki beklenti, vaka ve ölüm sayılarındaki artışların borsa oynaklığını negatif yönde etkileyeceği şeklindedir. Panel veri analizi, iki yönlü rassal etki modeli ile tahmin edilmiş ve her iki modelde de elde edilen sonuçların pozitif ve istatistiki olarak anlaml oldukları gözlemlenmiştir. Yani volatilite, vaka artış hızı \%1 arttı̆̆ında \%0,01 artarken, ölüm artış hızı \%1 arttı̆̆ında \%0,04 oranında artmaktadır.
Makale Geçmişi:

Iletilen Tarih:

23 Eylül 2021

Kabul Tarihi:

4 Arallk 2021

Jel Kodları:

C23, G01, G15

Anahtar Kelimeler: COVID-19 Pandemisi, Borsa Endeksi, Volatilite

Önerilen Alıntı: Yıldız B. \& Dam, M. M. (2022). Erken Dönem Covid-19 Pandemisinin Avrupa Borsalarındaki Volatiliteye Etkisinin Araştırılması. Cumhuriyet Üniversitesi İktisadi ve İdari Bilimler Dergisi, 23(1), 167-182.

${ }^{1}$ Dr. Öğr. Üyesi, Aydın Adnan Menderes Üniversitesi, İktisadi ve İdari Bilimler Fakültesi, Uluslararası Ticaret ve Finansman Bölümü, bulent.yildiz@ adu.edu.tr, ORCID: 0000-0001-6358-8620

${ }^{2}$ Doç. Dr., Aydın Adnan Menderes Üniversitesi, İktisadi ve İdari Bilimler Fakültesi, Uluslararası Ticaret ve Finansman Bölümü, metindam@adu.edu.tr, ORCID ID: 0000-0003-3980-7832 
Bülent YILDIZ \& Mehmet Metin DAM, 2022 Cilt: 23, Sayı: 1, ss.167-182.

\section{GÍRİŞ}

2020 yılında bütün dünyayı etkisi altına alan COVID-19 pandemisi, hem sosyal hem de ekonomik etkileri itibariyle hiçbir şeyin eskisi gibi olmayacağı yeni bir dünyanın kapısını aralamıştır. Bütün insanlığı etkileyen ve travmatik bir süreç yaşatan pandeminin insan yaşamına, çevreye, sosyal hayata ve ekonomiye olan etkisi akademik çevrelerin dikkatini üzerine çekmiş ve bu konu hakkında birçok akademik çalışma yapılmaya başlanmıştır. Önceki araştırmaların, SARS ve EBOLA gibi pandemilerin borsa performansı ile ilişkisine odaklandıkları görülürken, mevcut pandeminin büyüklüğü göz önüne alındığında, araştırmacıların COVID-19'un finansal piyasalar üzerindeki etkisine odaklandıkları görülmektedir(Baek vd., 2020: 1).

Pandemi dönemimde, deprem felaketinde olduğu gibi tehlikenin geçmesini bekleyip, daha sonra ekonomik hayatın normalleşmesi için çaba harcamak yerine salgın hastalığın devam ettiği gerçeğini gözden kaçırmadan sosyal hayatı normalleştirmeye çalışmak ve işletmelerin faaliyetlerine devam edebilmelerini sağlamak ortaya çıkabilecek ağır ekonomik kayıpları en aza indirecektir (Dam, 2021: 297). İhracatta yaşanan daralma, yoğun yabancı sermaye çıkış1, hammadde ve petrol fiyatlarında yaşanan düşüşler ülkelerin salgın sürecinde karşılaştıkları en büyük riskler olmuştur. Nitekim gelişmekte olan ülke piyasalarından tahvil ve bono satışları aracılığıyla 83 milyar dolara yakın sermaye çıkışı olmuş ve bunun sonucunda Meksika, Brezilya, Güney Afrika ve Rusya başta olmak üzere bu ülkelerin para birimleri dolar karşısında büyük oranda değer kaybına uğramıştır (Diaz-Bonilla, 2020). Dünyada yaşanan ve küresel çapta seyreden birçok krizin genelde ekonomi ve finansal faaliyetler üzerinde olumsuz etkiye sahip olduğu görülmektedir. Ancak sektörel bazda bakıldığında bu olumsuz etkilerin bazı sektörlerde daha derinden hissedildiği, bazı sektörlerde ise daha hafif seyrettiği söylenebilir. Hatta krizin bazı sektörlere pozitif yönde etki ettiğini söylemek de mümkündür (Kılıç, 2020: 68).

Finansal piyasaların işleyişi açısından önemli bir yere sahip olan volatilite, finansal varlıklardaki yatırımları çevreleyen finansal risk ve belirsizliğin bir göstergesi durumundadır. ABD finansal piyasalarında benzeri görülmemiş bir volatiliteye neden olan COVID-19 pandemisi nedeniyle CBOE Volatilite Endeksi (VIX) Mart 2020'de 80'nin üzerine çıkarak 2008'deki rekorunu kırmış, Nasdaq Composite ve S\&P500 endeksleri ise \%12 düşmüştür. Yine aynı gün (16 Mart 2020) Wall Street Journal, Dow Jones Sanayi Ortalamasının (DJIA) \%12'nin üzerinde düştüğünü ve 124 yıllık tarihindeki en kötü ikinci günü yaşadığını bildirmiştir (Baek vd., 2020: 1). COVID-19 pandemisinin borsaların volatilitesi üzerinde, yaşanmış diğer salgınlara nazaran daha ağır bir etkiye sahip olduğu gözlenmiştir (Baker vd., 2020:1). Bu durum mevcut pandeminin bir sağlık krizi olmasının yanında, aynı zamanda bir finansal kriz olarak da tanımlanmasına neden olmuştur (Ustalar ve Şanlısoy, 2021: 2).

$\mathrm{Bu}$ çalışmada erken dönem COVID-19 pandemisi vakalarının Avrupa borsalarındaki volatiliteye etkisinin incelenmesi amaçlanmıştır. Araştırmanın temel konusu, COVID-19 pandemisinin Avrupa borsalarını doğrudan etkileyen bir etken olup olmadığının araştırılmasıdır. Vaka ve ölüm artış hızlarının Avrupa'nın önemli borsalarının volatilitesi üzerideki etkisinin ortaya konulması bakımından literatüre önemli katkı sağlayacağı düşünülmektedir. Ayrıca yapılan literatür taramasında bu çalışmada yer alan Avrupa ülkeleri için 5 günlük tarihi volatilitenin Covid-19 vaka ve ölüm artış hızları ile karşılaştırıldığı bir çalışmaya rastlanılmamıştır. 


\section{ERKEN DÖNEM COVID-19 PANDEMISININ AVRUPA BORSALARINDAKI VOLATILITEYE ETKISININ ARASTTIRILMASI}

Çalışmanın bundan sonraki bölümünde literatür taramasına yer verilmiş olup, daha sonra araştırma yöntemi olarak kullanılan panel veri analizi tanıtılmış, en son bölümde ise sonuç ve değerlendirme yapılarak çalışma sonlandırılmıştır.

\section{LITERATÜR TARAMASI}

COVID-19 pandemisi ülke ekonomileri ile birlikte borsalarının da olumsuz olarak etkilenmesine neden olmuştur. $\mathrm{Bu}$ durum literatürde pandeminin hisse senedi piyasaları üzerindeki etkilerine yoğunlaşan çalışmaların artmasına neden olmuştur (Ustalar ve Şanlısoy, 2021: 2).

Albulescu (2021), Dünya Sağlık Örgütü (DSÖ) tarafindan açıklanan hem küresel hem de ABD'ye ait COVID-19 vaka sayıları ve ölüm oranlarının finansal piyasaların oynaklığı üzerindeki etkisini araştırmıştır. S\&P500 volatilite endeksinin oynaklık göstergesi olarak kullanıldığı çalışmanın analizi en küçük kareler yöntemi ile yapılmıştır. Elde edilen sonuçlara göre; vaka sayılarının finansal oynaklığı artırdığı, ölüm oranlarının oynaklık üzerinde pozitif bir etkiye sahip olduğu, küresel COVID-19 vaka sayılarının ABD'de açıklanan sayılara göre daha güçlü bir etkiye sahip olduğu tespit edilmiştir.

Engelhardt vd. (2021), güven faktörünün borsa oynaklığını etkileyip etkilemediğini 47 ülkenin hisse senedi piyasaları için araştırdığı çalışmasında, güven ölçütü olarak Dünya Değerler Araştırması'nın (World Values Survey's-WVS) son dalgasındaki (7. Dalga, 2017-2020) verileri kullanmışlardır. 22 Ocak 2020-29 Temmuz 2020 dönemini kapsayacak şekilde yapılan araştırmanın sonuçlarına göre, borsa oynaklığının yüksek güvene sahip ülkelerde daha düşük çıktığ1 görülmüştür.

Erdem (2020), Ocak 2020 ile Nisan 2020 dönemi için 75 ülkenin borsa getirileri ve oynaklığının COVID-19 vakalarından nasıl etkilendiğini araştırdığı çalışmasında, ülkelere ait özgürlük endeksi (Freedom House, 2019) rakamlarını da kullanmıştır. Panel regresyon yöntemiyle yapılan analizde elde edilen sonuçlara göre borsaların pandemiden olumsuz etkilendiği; getirilerin düştüğü, oynaklığın ise arttığı tespit edilmiştir. Vaka sayılarındaki artışın hisse getirileri üzerindeki etkisinin ölüm sayılarındaki artışın yarattığı etkinin yaklaşık üç katı kadar olduğu saptanmıştır. Ayrıca daha az özgür ülkelere nispeten daha özgür ülkelerin borsa getirilerindeki düşüşün daha sınırlı kaldığı, oynaklıkların ise daha düşük düzeyde seyrettiği bulunmuştur.

Uddin vd. (2021), çalışmalarında COVID-19'un borsa oynaklığı üzerindeki etkisini 01.07.2019-14.08.2020 dönemi için dinamik panel tabanlı bir EGARCH modeli ile incelemişlerdir. Gelişmiş ve gelişmekte olan 34 ülkenin yer aldığı çalışmada COVID-19 ile ilgili vaka ve ölüm sayıları, borsa getirileri, günlük işlem hacimleri ve günlük CBOE VIX volatilite endeksine ait veriler kullanılmıştır. Çalışmanın sonuçlarına göre; COVID-19 vaka ve ölüm sayılarındaki büyümenin borsa getirilerini negatif olarak etkilediği, yine vaka ve ölüm sayılarındaki büyümenin hisse senedi piyasasının koşullu varyansı ile pozitif yönde ve anlamlı bir ilişkiye sahip olduğu tespit edilmiştir.

Özkan (2020) COVID-19 salgınının BIST endekslerinin zımni oynaklıkları üzerindeki etkisini araştırdığı çalışmasında, Mart 2020 döneminde bütün endekslerde önemli derecede oynaklık/volatilite artışı tespit etmiştir. Yazar en yüksek volatilite sıçramasını \%15,7 ile spor 
Bülent YILDIZ \& Mehmet Metin DAM, 2022 Cilt: 23, Sayı: 1, ss.167-182.

sektörü hisselerinde bulurken, en düşük volatilite sıçramasını ise \%2 ile sigorta endeksindeki hisseler için bulmuştur.

Yağlı (2020) çalıșmasında COVID-19'un borsa oynaklığı üzerindeki etkisi ile birlikte farklı sektörlere olan etkisini de araştırmıştır. Yazarın elde ettiği sonuçlara göre COVID-19 döneminde bütün sektörler için volatilitede önemli derecede bozulma olduğu tespit edilmiş, özellikle hizmet sektöründeki bozulmanın daha belirgin olduğu bulunmuş, ancak COVID-19'un Türkiye özelinde hisse senedi piyasası oynaklığının ana aktörü olmadığı saptanmıştır. Ayrıca kredi temerrüt takası (credit default swaps-CDS) oranlarının hisse senedi piyasası oynaklığını artırırken, döviz kurunun oynaklığ 1 azalttığı tespit edilmiştir.

Onali (2020) COVID-19 vakaları ve ilişkili ölümlerin Dow Jones ve S\&P500 endeks getirileri ve volatiliteleri üzerindeki etkisini araştırdığı çalışmasını 08 Nisan 2019- 09 Nisan 2020 dönemini içine alacak şekilde yapmıştır. Araştırmacının elde ettiği sonuçlara göre; ABD ve COVID-19'dan büyük ölçüde etkilenen diğer ülkelerin (İtalya, Fransa, Çin, İngiltere, İspanya, İran) vaka ve ölüm sayılarındaki değişikliklerin, Çin vaka sayılarının haricinde, ABD borsa getirileri üzerinde bir etkiye sahip olmadığı saptanmıştır. Ayrıca VAR modelleri ile İtalya ve Fransa' daki ölüm sayılarının VIX endeksi üzerinde pozitif bir etki oluşturduğu tespit edilmiştir.

Baek vd. (2020) Ocak 2020 ile Nisan 2020 arasındaki dönem için yaptıkları çalışmada COVID-19 pandemisinin ABD borsa oynaklığı üzerindeki etkisini araştırmışlardır. Araştırma sonuçlarına göre borsa oynaklığındaki değişimin ekonomik değişkenlerden ziyade COVID-19 haberlerine daha duyarlı olduğu tespit edilmiştir.

\section{AMPIRIK ANALIZ}

\subsection{Veri Seti}

Bu çalışmada 16 ülkenin (İngiltere, Almanya, İsviçre, İsveç, İtalya, İrlanda, Belçika, Norveç, Avusturya, Danimarka, Hollanda, Fransa, İspanya, İzlanda, Portekiz Türkiye) 17.02.2020 - 24.04.2020 dönemine ait günlük verileri kullanılmıştır. Volatilite, vaka ve ölüm artış hızı değişskenlerine ait veriler Tablo 1'de verilmiştir.

Tablo 1: Veri Seti

\begin{tabular}{|c|c|c|c|c|c|c|}
\hline Değişken & Sembol & Temsil Eden Değişken & Kullanımı & Kaynak & Kullanılış Amacı & $\begin{array}{c}\text { Referans } \\
\text { Alınan } \\
\text { Çalışmalar }\end{array}$ \\
\hline Volatilite & $V L$ & Borsa oynaklığ 1 & Oran & $\begin{array}{c}\text { Dünya } \\
\text { Bankas1 } \\
\text { WDI }\end{array}$ & Bağımlı Değişken & $\begin{array}{l}\text { Albulescu, } \\
\text { (2020) }\end{array}$ \\
\hline $\begin{array}{c}\text { Vaka Artış } \\
\text { Hızı }\end{array}$ & $V A$ & $\begin{array}{c}\text { COVID-19 } \\
\text { pandemisindeki vaka } \\
\text { artış hızı }\end{array}$ & Oran & $\begin{array}{l}\text { Dünya } \\
\text { Sağlık } \\
\text { Örgütü }\end{array}$ & $\begin{array}{l}\text { COVID } 19 \text { vaka artış } \\
\text { hızının borsa üzerindeki } \\
\text { etkisini tespit edebilmek }\end{array}$ & $\begin{array}{l}\text { Albulescu, } \\
\text { (2020); Erdem } \\
\text { (2020); Uddin } \\
\text { vd. (2021) }\end{array}$ \\
\hline $\begin{array}{c}\text { Ölüm Artış } \\
\text { Hızı }\end{array}$ & $O A$ & $\begin{array}{c}\text { COVID-19 } \\
\text { pandemisindeki ölüm } \\
\text { artış hızı }\end{array}$ & Oran & $\begin{array}{l}\text { Dünya } \\
\text { Sağlık } \\
\text { Örgütü }\end{array}$ & $\begin{array}{l}\text { COVID } 19 \text { ölüm artış } \\
\text { hızının borsa üzerindeki } \\
\text { etkisini tespit edebilmek }\end{array}$ & $\begin{array}{l}\text { Albulescu, } \\
\text { (2020); Erdem } \\
\text { (2020); Uddin } \\
\text { vd. (2021) }\end{array}$ \\
\hline
\end{tabular}

Finansal piyasalarda riskin bir göstergesi olarak kabul edilen volatilite, piyasa dinamikleri açısından önemli bir role sahip temel göstergelerden birisidir. Belirli bir zaman diliminde bir 


\section{ERKEN DÖNEM COVID-19 PANDEMISININ AVRUPA BORSALARINDAKI VOLATILITEYE ETKISINIIN ARASTTIRILMASI}

varlığın getirisinin standart sapması şeklinde ifade edilebilen volatilitenin hesaplanmasında iki temel yaklaşım söz konusudur. Birinci yaklaşıma göre volatilite, geçmiş veya gerçekleşen verilere dayalı olarak hesaplanan tarihi volatilite olurken; ikinci yaklaşıma göre ise opsiyon fiyatları baz alınarak hesaplanan, öngörülen volatilitedir. Belirsizliğin arttı̆̆ dönemlerde volatilitenin genellikle yükseldiği, öngörülen volatilitenin genelde gerçekleşen volatiliteden daha yüksek çıktığı görülmektedir. Bu çalışmanın da konusu olan tarihi volatilite, bir finansal varlığın geçmiş bir döneme ait fiyatlarının standart sapmasıdır. Gerçekleşen volatilite olarak da adlandırılan tarihi volatilite geçmiş fiyat bilgisi baz alınarak hesaplanır (Karabıyık ve Anbar, 2007: 76).

Çalışmada kullanılan volatilite değerleri hesaplanırken BİST risk kontrol endeksleri temel kuralları dokümanında (borsaistanbul.com) ve Karabıyık ve Anbar (2007) çalışmalarında geçen ve aşağıda gösterilen formüllerden yararlanılmıştır:

$\operatorname{Vol}_{t, n}=\sqrt{252 \frac{1}{n} \sum_{i=1}^{n}\left(R_{t-i+1}-\bar{R}_{t, n}\right)^{2}}$

$R_{t}=\ln \left(E_{t} / E_{t-1}\right)$

$\bar{R}_{t, n}=\frac{1}{n} \sum_{i=1}^{n} R_{t-i+1}$

$\mathrm{Vol}_{\mathrm{t}, \mathrm{n}}: \mathrm{n}$ işlem günü için tarihi volatilite

$\mathrm{E}_{\mathrm{t}}$ : Endeks kapanış değeri

$\mathrm{n}$ : Volatilitenin hesaplandığı gün sayısı

COVID-19 verileri, 25.04.2020 tarihinde DSÖ tarafından yayınlanan günlük durum raporlarından alınmıştır. Sonuç olarak, örneğimiz Covid-19 vakalarının bazı Avrupa ülkelerinde 1'er 2'şer görülmeye başlandığı şubat ayının ortalarında başlayıp 17.02.2020-24.04.2020 dönemini kapsamaktadır (16 ülke, 48 gözlem). Borsa endekslerine ait 5 günlük oynaklık verileri günlük endeks getirileri kullanılarak Excel ortamında hesaplanmıştır. Vaka artış hızı (VA) ve ölüm artış hızı (OA) verileri Dünya Sağlık Örgütü web sitesinden alınmıştır.

Tablo 2, modele alınan değişkenlerine ait tanımlayıcı istatistikler sunulmuştur.

Tablo 2: Değişkenlerin Tanımlayıcı İstatistikleri

\begin{tabular}{cccc}
\hline & VL & VA & OA \\
\hline Minimum & 0.035 & -0.899 & 0.000 \\
\hline Maksimum & 1.423 & 20.416 & 4.000 \\
\hline Ortalama & 0.391 & 0.340 & 0.230 \\
\hline Medyan & 0.340 & 0.114 & 0.070 \\
\hline Standart Sapma & 0.227 & 1.015 & 0.411 \\
\hline
\end{tabular}


Bülent YILDIZ \& Mehmet Metin DAM, 2022 Cilt: 23, Sayl: 1, ss.167-182.

\subsection{Model}

Bu çalışmada COVID-19 pandemi süresince 15 Avrupa ülkesi ve Türkiye’de yaşanan vaka ve ölüm sayılarının ülkelerindeki borsa endeksleri üzerindeki etkisi incelenmiştir. Bu çalışmadaki beklenti vaka ve ölüm sayılarındaki artışların borsa oynaklığını negatif yönde etkileyeceği şeklindedir. Çalışmada iki model tahmin edilmiş olup; Aghion ve Howitt (1992: 342), Dam ve Yıldız (2016: 229) çalışmaları göz önünde bulundurulmuştur.

Model 1: $V L_{i t}=\alpha_{0 i}+\alpha_{1 i} V A+\varepsilon_{i t}$

Model 2: $V L_{i t}=\beta_{0 i}+\beta_{1 i} O A+v_{i t}$

\subsection{Yöntem}

Modele alınan birçok ülkenin hem yatay kesit hem de zaman boyutunu inceleyebilmek için panel veri analizi yöntemi kullanılmıştır. Panel veri analizinin zaman serisi ve yatay kesit analizinden üstün birçok yanı bulunmaktadır. Bu bağlamda çok gözlemle analiz yapmak daha doğru tahmin sonuçları vermektedir. Panel veri analizi (Gujarati, 1999; Baltagi, 2001):

$$
Y_{i t}=\alpha+X_{i t}^{\prime} \beta+u_{i t}
$$

Denklem 6'da $Y$; bağımlı değişkeni, $\alpha$; sabit sayı, $X$; bağımsız değişkeni, $\beta$; bağımsız değişken katsayısını ve $u$; hata terimini göstermektedir. Ayrıca modeldeki $i$; ülkeleri ve $t$; de zaman boyutunu ifade etmektedir. Denklem 6'daki hata terimi ayrıştırıldığında;

$$
u_{i t}=\mu_{i}+\lambda_{t}+v_{i t}
$$

şeklinde denklem elde edilmiştir. Denklem 7 aynı zamanda hata bileşeni modeli (error component model) olarak adlandırılmaktadır. Denklemde bireysel etkileri $\mu_{i}$, zaman etkilerini ise $\lambda_{i}$ temsil etmektedir. $\mu_{i}, \lambda_{t} v e v_{i t} \approx I I D\left(0, \sigma^{2}\right)$ hata terimi ortalamasının sıfir, varyansının sabit olduğu ve normal dağılım gösterdiği varsayılmaktadır.

Panel veri analizinde yapılan tahminlerin sapmalı çıkmaması için öncelikle birim kök testi sınaması yapılmaktadır. Panel birim kök testi sonuçlarına göre en uygun tahminci seçilmektedir.

\subsubsection{Panel Birim Kök Testi}

$\mathrm{Bu}$ çalışmada, serilerin durağanlığını test etmek için Levin, Lin ve Chu (2002) (LLC) panel birim kök testi tercih edilmiştir. LLC panel birim kök testinde serilerin önceki gecikmelerinden etkilenme dereceleri AR(1) sürecinin baz alınmasıyla incelenmektedir.

$$
Y_{i t}=\rho Y_{i t-1}+e_{i t}
$$

Burada, ortak bir birim kökün varlığı test edilmektedir. Testin hipotezleri:

$$
\begin{aligned}
& H_{0}:|\rho|=1 \text { seri durağan değil; } \\
& H_{0}:|\rho|<1 \text { seri durağandır, şeklindedir. }
\end{aligned}
$$

Tablo 4'te değişkenlerin durağanlıkları ile ilgili kullanılan yöntem (LLC) ve sonuçlar verilmiştir. 
ERKEN DÖNEM COVID-19 PANDEMISIININ AVRUPA BORSALARINDAKI

VOLATILITEYE ETKISININ ARASTTIRILMASI

Tablo 4: LLC Panel Birim Kök Testi Sonuçları

\begin{tabular}{ccc}
\hline Değişken & Düzey Değeri & Olasilik Değeri \\
\hline $\boldsymbol{V} \boldsymbol{L}$ & $-1.69^{*}$ & 0.044 \\
\hline $\boldsymbol{V A}$ & $-10.67 * *$ & 0.000 \\
\hline $\boldsymbol{O A}$ & $-7.98 * *$ & 0.000
\end{tabular}

Not: * ve ** sırası ile \%5 ve \%1 anlamlılık düzeyinde serinin durağanlığını göstermektedir.

LM testi panel veri analizinde modele alınan serilerin bireysel etkilerinin ve zaman etkilerinin türünün belirlenmesi amacıyla yapılmaktadır. Yani LM testinde tahminci seçiminde rassal veya sabit etkiler modelinin seçimi yapılmaktadır (Baltagi. 2001: 15).

LM1, LM2 ve LM şeklinde üç test olarak yapılan LM testleri sırasıyla bireysel etkileri, zaman etkilerini ve hem bireysel hem de zaman etkilerini ölçmektedir.

LM1 testi için; $H_{0}: \sigma_{\mu}^{2}=0$ bireysel etkiler yoktur, şeklindedir ve test istatistiği aşağıda belirtilen formül aracılığgyla hesaplanmaktadır.

$$
L M_{1}=\frac{N . T}{2 .(T-1)}\left[\frac{\sum_{i=1}^{N}\left(\sum_{t=1}^{T} \hat{\mathrm{u}}_{\mathrm{it}}\right)^{2}}{\sum_{i=1}^{N} \sum_{t=1}^{T} \hat{\mathrm{u}}_{\mathrm{it}}^{2}}-1\right]^{2}
$$

Denklem 9'daki formülde hesaplanan "olasılık değeri" $<0.05$ olduğu durumda, $\mathrm{H}_{0}$ reddedilerek bireysel etkilerin rassallığına karar verilir.

LM2 testinde; $H_{0}: \sigma_{\lambda}^{2}=0$ Zaman etkileri yoktur şeklindedir ve test istatistiği aşağıdaki formülle hesaplanmaktadir.

$$
L M_{2}=\frac{N . T}{2 .(N-1)}\left[\frac{\sum_{t=1}^{T}\left(\sum_{n=1}^{T N} \hat{\mathrm{u}}_{\mathrm{it}}\right)^{2}}{\sum_{i=1}^{N} \sum_{t=1}^{T} \hat{\mathrm{u}}_{\mathrm{it}}^{2}}-1\right]^{2}
$$

Denklem 10'daki formülde elde edilen olasılık değeri aynı Denklem 9'daki gibi 0.05'ten küçük olduğu zaman, $\mathrm{H}_{0}$ reddedilerek zaman etkilerinin rassal olduğuna karar verilir.

$L M=L M_{1}+L M_{2}$ testinde;

$H_{0}: \sigma_{\mu}^{2}=\sigma_{\lambda}^{2}=0$ Bireysel etkiler ve zaman etkileri yoktur,

$H_{1}: \sigma_{\mu}^{2} \neq 0$ veya $\sigma_{\lambda}^{2} \neq 0$ ya da her ikisi de $\neq 0$ etkilerden en az biri ya da ikisi de rassaldır, şeklindedir.

LM1 LM2 ve LM testlerinde bulunan "olasılık değerleri” $<0.05$ olduğu durumda, $\mathrm{H}_{0}$ reddedilmekte ve bireysel etkiler ile zaman etkilerinin rassallı̆̆ kabul edilmektedir. (Mercan vd. 2013). Tablo 5 ve Tablo 6'da Model 1 ve Model 2 için test sonuçları verilmiştir. 
Bülent YILDIZ \& Mehmet Metin DAM, 2022 Cilt: 23, Sayı: 1, ss.167-182.

Tablo 5: LM Testleri: Model 1: Volatilite $=\mathrm{f}(\mathrm{VA})$

\begin{tabular}{|c|c|c|}
\hline Test & Olasılık Değeri & Karar \\
\hline $\mathrm{LM}_{1}$ & 0.000 & Bireysel Etkiler Rassaldır \\
\hline $\mathrm{LM}_{2}$ & 0.000 & Zaman Etkileri Rassaldır \\
\hline $\mathrm{LM}$ & 0.000 & Bireysel Etkiler ve Zaman Etkileri Rassaldır \\
\hline
\end{tabular}

Tablo 5'teki Model 1'in sonuçlara bakıldığında LM1, LM2 ve LM testlerinin olasılık değerleri 0.05 'den küçük olduğu için etkilerin rassal olduğuna karar verilmiştir.

Tablo 6: LM Testleri: Model 2: Volatilite $=\mathrm{f}(\mathrm{OA})$

\begin{tabular}{|c|c|c|}
\hline Test & Olasılık Değeri & Karar \\
\hline LM1 & 0.000 & Bireysel Etkiler Rassaldır \\
\hline LM2 & 0.000 & Zaman Etkileri Rassaldır \\
\hline LM & 0.000 & Bireysel Etkiler ve Zaman Etkileri Rassaldır \\
\hline
\end{tabular}

Tablo 6'daki Model 2'in sonuçlara bakıldığında Model 1'deki gibi LM1, LM2 ve LM testlerinin olasılık değerleri 0.05 'den küçük olduğu için etkilerin rassal olduğuna karar verilmiştir.

\subsubsection{Hausman Testi}

İçsellik problemi ve LM testi doğrulması olarak yapılan Hausman testi Moldel 1 ve Model 2 için ayrı ayrı test edilmiştir. Testin hipotezleri;

$$
\begin{aligned}
& H_{0}: \operatorname{Cov}\left(\mu_{i}, x_{i t}\right)=0 \text { İçsellik problemi yoktur, } \\
& H_{0}: \operatorname{Cov}\left(\mu_{i}, x_{i t}\right) \neq 0 \text { İçsellik problemi vardır, şeklindedir. }
\end{aligned}
$$

Hipotezlerdeki $\mu_{i t}$ Denklem 7'deki bireysel etkileri, $X_{i t}$ ise Denklem 6'daki açıklayıcı değişkenleri ifade etmektedir. Hausman test sonucunda eğer $X^{2}$ değeri (Chi2=Kikare) 0.05 'ten küçük olursa $\mathrm{H}_{0}$ hipotezi reddedilir ve modelin içsellik problemi olduğuna karar verilir. İçsellik probleminin olduğu modelde sabit etkiler, içsellik probleminin olmadığı modelde ise rassal etkiler modeli kullanılır (Greene, 2003).

Çalışmada Model 1 ve Model 2 için yapılan Hausman test sonuçlarında, Model 1 için $X^{2}$ $=0.570$ ve $X^{2}$ olasılık değeri 0.450 , Model 2 için $X^{2}=2.239$ ve $X^{2}$ olasılık değeri 0.134 olarak hesaplanmıştır. Hesaplanan bu değerler 0.05 'ten büyük olduğu için $\mathrm{H}_{0}$ hipotezi kabul edilmiş ve her iki modelde de içsellik probleminin olmadığına karar verilmiştir. Çıkan bu test sonuçlarına göre analizin rassal etkiler modeli ile yapılmasına karar verilmiştir.

\subsubsection{Rassal Etkiler Model Tahmini}

LM testi ve Hausman test sonuçlarına göre çalışmaya alınan her iki modelin rassal etkiler yöntemi ile tahmin edilmesine karar verilmiş ve tahmin sonuçları Tablo 7'de özetlenmiştir. 


\section{ERKEN DÖNEM COVID-19 PANDEMISININN AVRUPA BORSALARINDAKI \\ VOLATILITEYE ETKISININ ARAŞTIRILMASI}

Tablo 7: Rasssal Etkiler Modeli Tahmin Sonuçları

\begin{tabular}{|c|c|c|c|c|c|}
\hline \multirow{2}{*}{ Değişken } & \multicolumn{2}{|c|}{ Model 1} & \multirow[t]{2}{*}{ Değişken } & \multicolumn{2}{|l|}{ Model 2} \\
\hline & Katsayı & t-İstatistiğ & & Katsayı & t-İstatistiği \\
\hline $\mathrm{VL}_{(-1)}$ & 0.868 & 51.343 & $\mathrm{VL}_{(-1)}$ & 0.841 & 47.266 \\
\hline VA & 0.010 & 2.802 & $\mathrm{OA}$ & 0.043 & 4.390 \\
\hline Sabit Terim & 0.052 & 6.709 & Sabit Terim & 0.056 & 7.380 \\
\hline \multicolumn{6}{|c|}{ Tanisal Testler } \\
\hline \multicolumn{3}{|c|}{ Model 1} & \multicolumn{3}{|c|}{ Model 2} \\
\hline $\mathrm{DW}=2.10$ & \multicolumn{2}{|c|}{$F_{\text {ist }}=1343.67(0.000)$} & \multicolumn{2}{|c|}{$\mathrm{DW}=2.10$} & $69.37(0.000)$ \\
\hline
\end{tabular}

Tablo 7'de verilen tanısal test sonuçları incelendiğinde her iki modelin de istatistiksel olarak güvenilir ve yorumlanabilir olduğu görülmektedir. Bununla birlikte her iki model için de bulunan sonuçların pozitif ve istatistiksel olarak anlamlı olduğu tespit edilmiştir. Volatilite, vaka artış hızı $\% 1$ arttığında \%0,01 artarken, ölüm artış hızı \%1 arttığında \%0,04 oranında artmaktadır. Elde edilen bu sonuçlara göre pandeminin kısa dönemde Avrupa borsalarının oynaklığı üzerinde istatistiksel olarak anlamlı bir etkiye sahip olduğu görülmektedir. 
Bülent YILDIZ \& Mehmet Metin DAM, 2022 Cilt: 23, Sayı: 1, ss.167-182.

\section{SONUÇ VE DEĞERLENDİRME}

COVID-19 virüsünün kısa süre içerisinde bir pandemi haline dönüşmesi sonrasında, hayatın diğer alanlarında olduğu gibi finansal piyasalarda da bir panik hali yaşanmıştır. Pandeminin ilk aylarında virüsün kontrol altına alınmasında yaşanan zorluklar ve belirsizlik hem sosyal, hem de ekonomik hayatı olumsuz etkilemiştir. Tedbir amaçlı kapanan işletmeler ve sosyal hayata kısıtlama getiren tedbirler ve bu tedbirlerin ne zaman son bulacağı hakkındaki belirsizlik ile birlikte dünya ticaret hacminin önemli oranda olumsuz etkilendiği bir tablo ortaya çıkmıştır. Bu olumsuz tablodan dünya borsaları da etkilenmiştir.

Çalışmada pandeminin Avrupa borsalarındaki volatiliteye etkisi araştırılmıştır. Panel veri analizi yönteminin kullanıldığı araştırmada, çalışmanın yapıldığ 1 dönem için vaka ve ölüm sayılarının nüfusa göre en yüksek olduğu 15 Avrupa ülkesi ile birlikte Türkiye de dahil edilmiştir. Çalışmada pandeminin ülkelerin borsa endekslerindeki volatiliteye etkisi araştırılırken, 17.02.2020 - 24.04.2020 dönemine ait günlük veriler kullanılmıştır. Değişken olarak vaka sayıları, ölüm oranları ve volatilite kullanılmış olup iki model tahmin edilmiştir. Panel Birim Kök Testi, LM Testi, Hausman Testi ve Rassal Etkiler Model tahmininin yapıldığı bu çalışmadaki beklenti, vaka ve ölüm sayılarındaki artışların borsa oynaklığını negatif yönde etkileyeceği şeklindedir. Bu bağlamda çalışmada iki model tahmin edilmiştir.

Serilerin durağanlığı LLC panel birim kök testiyle analiz edilmiştir. Tüm serilerin düzeyde durağan oldukları yani $I(O)$ oldukları görülmüştür. $\mathrm{Bu}$ durumda seriler arasındaki etkileşimin boyutu, panel EKK yöntemleriyle tahmin edilebilmiştir. Tahmincinin belirlenmesinde önce LM testleri yapılmış ve sonra Hausman testleri yapılarak tahminci seçimi doğrulanmıştır. LM testleri sonuçları incelendiğinde, hem bireysel etkiler hem de zaman etkilerinin rassal olduğu tespit edilmiş ve tahminin rassal etki modeli ile yapılmasına karar verilmiştir.

Daha sonra Hausman testi yapılarak içsellik probleminin olup olmadığına bakılmıştır. Hausman testi sonuçlarına göre, Model 1 için $X^{2}=0.570$ ve $X^{2}$ olasılık değeri 0.450; Model 2 için $X^{2}=2.239$ ve $X^{2}$ olasıllk değeri 0.134 olarak bulunmuştur. Bu değerlerin 0.05 'ten büyük olması nedeniyle, modellerde içsellik probleminin olmadığı tespit edilmiştir. $\mathrm{Bu}$ aşamada, analizin rassal etkiler modeliyle yapılması gerektiği ortaya çıkmıştır. Panel veri analizinin, rassal etki modeli ile tahmin edildiği çalışmada, her iki modelde elde edilen sonuçların (vaka artış hızı ve ölüm artış hızının volatilite üzerindeki etkisi) pozitif ve istatistiki olarak anlamlı oldukları görülmektedir. Elde edilen bu sonuç, literatürdeki Erdem (2020); Albulescu (2021) ve Uddin vd. (2021) ile uyumludur. Yani volatilite, vaka artış hızı \%1 arttığında \%0,01 artarken, ölüm artış hızı \%1 arttığında \%0,04 oranında artmaktadır.

COVID-19 pandemisinin etki alanına bakıldığında bunun sadece bir sağlık sorunu olduğunu söylemek mümkün görünmemektedir. Daha önceki benzer salgınlardan farklı olarak (sonuçları itibariyle) bütün dünyada ekonomik yaşam üzerinde önemli bir tahribata sebep olduğu görülmektedir. Ülkelerin çözüm çabalarına bakıldığında bu ve benzeri krizlerde birlikte hareket etmenin önemi ortaya çıkmaktadır. Ayrıca toplumların, küreselleşmenin de etkisiyle, sağlık temelli fakat başta ekonomi olmak üzere iş ve sosyal hayatı etki altına alan benzer sorunları bundan sonraki süreçte de yaşaması muhtemeldir. Yapılan akademik çalışmalar ile COVID-19 ve benzeri krizlerin sosyal ve ekonomik hayata olan etkisi ve ilişkisi araştırılmaya çalışılmaktadır. $\mathrm{Bu}$ çalışma ile elde edilen sonuçların Türkiye ve Avrupa ülkelerindeki borsalarda pandeminin etkisinin ortaya konulması amaçlanarak daha sonraki muhtemel krizlerde finansal piyasa muhataplarına 1şık tutulması amaçlanmıştır. 


\section{ERKEN DÖNEM COVID-19 PANDEMISININ AVRUPA BORSALARINDAKI \\ VOLATILITEYE ETKISININ ARAŞTIRILMASI}

Daha sonra yapılacak çalışmalarda uzun vadede pandemi nedeniyle ortaya çıkan vaka ve ölüm sayılarının, alınan tedbirlerin ve aşılama faaliyetlerinin dünya borsaları üzerindeki etkisi araştırılabilir. Finansal piyasaların bu tür krizlerde daha derinden etkilenmemesi için erken teşhis ve uyarı mekanizmaları üzerinde çalışılması gerekmektedir. Bir yandan bu ve benzeri salgınlarla etkin bir şekilde mücadele ederken, bir yandan da ekonomi, iş ve sosyal hayatın devamını sağlayacak tedbirlerin zamanında alınması oldukça önemlidir. 
Bülent YILDIZ \& Mehmet Metin DAM, 2022 Cilt: 23, Sayı: 1, ss.167-182.

\section{KAYNAKÇA}

Albulescu, C. T. (2021). COVID-19 and the United States Financial Markets' Volatility. Finance Research Letters, 38, 101699.

Albulescu, C. (2020). Coronavirus and Oil Price Crash. http://doi.org/10.2139/ssrn.3553452

Aghion, P., \& Howitt, P. (1992), A Model of Growth Through Creative Destruction. Econometrica, 60(2), 323-351.

Baek, S., Mohanty, S. K., \& Glambosky, M. (2020). COVID-19 and Stock Market Volatility: An Industry Level Analysis. Finance Research Letters, 37, 101748.

Baltagi B. H. (2001). Econometric Analysis of Panel Data. (2nd ed). John Wiley \& Sons.

Dam, M. M. (2021). Environmental Benefits of the COVID-19 Pandemic. Y. Kaderli \& E. Çakır (Eds.) Contemporary Issues with Multidisciplinary Perspectives on Social Sciences (1 rd ed.) 293-304. Peter Lang.

Dam, M. M., \& Yildı, B. (2016). BRICS-TM Ülkelerinde Ar-Ge ve İnovasyonun Ekonomik Büyüme Üzerine Etkisi: Ekonometrik Bir Analiz. Akdeniz Üniversitesi Íktisadi ve İdari Bilimler Fakültesi Dergisi, 16(33), 220-236.

Diaz-Bonilla, E. (2020). Fiscal and Monetary Responses to the COVID-19 Pandemic: Some Thoughts for Developing Countries and the International Community. IFPRI, 98-101.

Engelhardt, N., Krause, M., Neukirchen, D., \& Posch, P. N. (2021). Trust and Stock Market Volatility During the COVID-19 Crisis. Finance Research Letters, 38, 101873.

Erdem, O. (2020). Freedom and Stock Market Performance During Covid-19 Outbreak. Finance Research Letters.

Gujarati, D. N. (1999). Temel Ekonometri. Ü. Şenesen (Çev.), Gülay Günlük Senesen, Literatür Yayıncılık, 7. Basım, Eylül 2010.

Greene, W. H. (2003). Econometric Analysis. Pearson Education.

Karabıyık, L., \& Anbar, A. (2007). Volatilite ve Varyans Swaplar1. Muhasebe ve Finansman Dergisi, (35), 62-77.

Kilıç, Y. (2020). Borsa İstanbul'da COVID-19 (Koronavirüs) Etkisi. JOEEP: Journal of Emerging Economies and Policy, 5(1), 66-77.

Levin, A., Lin, C. F., \& Chu, C.S.J. (2002). Unit Root Tests in Panel Data: Asymptotic and Finite-Sample Properties, Journal of Econometrics, 108, 1-24.

Mercan, M., Göçer, İ., Bulut, Ş., \& Dam, M. (2013). The Effect of Openness on Economic Growth for BRIC-T Countries: Panel Data Analysis. Eurasian Journal of Business and Economics, 6(11), 1-14.

Onali, E. (2020). Covid-19 and Stock Market Volatility. http://doi.org/10.2139/ssrn.3571453

Özkan, O. (2020). Volatility Jump: The Effect of COVID-19 on Turkey Stock Market. Gaziantep Üniversitesi Sosyal Bilimler Dergisi, 19(COVID-19 Special Issue), 386-397. 


\section{ERKEN DÖNEM COVID-19 PANDEMISININ AVRUPA BORSALARINDAKI \\ VOLATILITEYE ETKISININ ARAŞTIRILMASI}

Uddin, M., Chowdhury, A., Anderson, K., \& Chaudhuri, K. (2021). The Effect of COVID-19 Pandemic on Global Stock Market Volatility: Can Economic Strength Help to Manage the Uncertainty?. Journal of Business Research, 128, 31-44.

Ustalar, S. A., \& Şanlısoy, S. (2021). COVID-19 Krizi’nin Türkiye ve G7 Ülkelerinin Borsa Oynaklıkları Üzerindeki Etkisi. Eskişehir Osmangazi Üniversitesi İktisadi ve İdari Bilimler Dergisi, 16(2), 446-462.

Yağlı, İ. (2020). The Impact of Covid-19 on Emerging Stock Market Volatility: Empirical Evidence from Borsa Istanbul. Ekonomi Politika ve Finans Araşttrmaları Dergisi, 5(Özel Say1), 269-279.

https://www.worldvaluessurvey.org/wvs.jsp

https://freedomhouse.org/ 
Bülent YILDIZ \& Mehmet Metin DAM, 2022 Cilt: 23, Sayı: 1, ss.167-182.

\section{EXTENDED ABSTRACT}

The impact of the COVID-19 pandemic, which affected all humanity and caused a traumatic process, on human life, the environment, social life and the economy attracted the attention of academic circles. Many academic studies have been started on this subject. Among them, investigating the effect of the pandemic on stock markets have an important place. For instance, Albulescu (2021), using the S\&P500 volatility index as an indicator of volatility, stated that the number of COVID-19 cases increased financial volatility and death rates had a positive effect on volatility, while Uddin et al. (2021) revealed that the growth in the number of COVID19 cases and deaths negatively affects the stock market returns, and the growth in the number of cases and deaths has a positive and significant relationship with the conditional variance of the stock market. Similar studies investigating the effect of the COVID-19 pandemic on stock market volatility were also brought to the literature by researchers such as Erdem (2020), Özkan (2020), Yagli (2020), Onali (2020), Baek et al. (2020).

The aim of this study is to investigate the effect of the number of cases and deaths caused by the early period COVID-19 pandemic on the volatility in European stock markets. The study is important in the short term in terms of measuring the reaction of the markets to COVID-19 and sharing the results and contributing to the preparation of the markets for possible similar crisis periods.

In the study, the effect of the pandemic on the volatility in the European stock markets was investigated. In order to examine the data of different countries together, the panel data analysis method was used. Albulescu (2020), Erdem (2020) and Uddin et al. (2021) studies were taken as a reference in the study, in which the effect of the number of cases and deaths on the volatility of the stock markets was tested with the panel data analysis method. Turkey was included in the analysis, along with 15 European countries (England, Germany, Switzerland, Sweden, Italy, Ireland, Belgium, Norway, Austria, Denmark, Netherlands, France, Spain, Iceland, Portugal) with the highest number of cases and deaths by population for the period of the study. While investigating the effect of the pandemic on the volatility in the stock market indices of the countries (DAX, ATX, BEL20, FTSE100, OMXC20, AEX, CAC40, FTSE MIB, IBEX35, ISEQ, SMI, OMXIPI, BIST100), daily data for the period 17.02.2020 - 24.04.2020 were used. Case numbers, death rates and volatility were used as variables and two models were estimated. Stata 15 and EViews 12 econometric analysis programs were used for analysis, and codes were used for model selection and validation tests (variance and autocorrelation). The expectation in this study, in which the panel unit Root Test, the Breush - Pagan Lagrange Multiplier (LM) test, the Hausman endogeneity test, and the two-way random effects model estimate, is that increases in the number of cases and deaths will negatively affect stock market volatility. In this context, the two models used in the study were estimated by following the studies of Aghion and Howitt (1992: 342), Dam and Y1ld1z (2016: 229).

The stationarity of the series was investigated by the Levin, Lin and Chu (2002) (LLC) test. It was observed that all series were stationary in level, that is, they were $I(0)$. In this case, the size of the interaction between the series could be estimated by panel least square methods (LSM). While choosing the panel LSM method used, the fact that the effects are fixed or random or that there are no effects was important in determining the estimation method. Since the countries included in the analysis were chosen randomly in this study, LM tests were performed first, with the expectation that the effects would be random, and the Hausman endogeneity test was used to test the results obtained from this study. When the LM test results are examined, it is 


\section{ERKEN DÖNEM COVID-19 PANDEMISININ AVRUPA BORSALARINDAKI VOLATILITEYE ETKISININ ARAŞTIRILMASI}

seen that the individual effects and time effects are random and the estimation was made with a two-way random effects model. Then, whether there is a relationship (endogeneity problem) between individual effects and explanatory variables was tested with the Hausman endogeneity method. According to the Hausman test results, Chi2 $=0.570$ and Chi 2 probability value $=0.450$ for model 1 , Chi2 $=2.239$ and Chi2 probability value $=0.134$ for model 2 , it was decided that there was no endogeneity problem in the model since this value was greater than 0.05 . In this case, the analysis should be done with a random effects model. In the study, in which the panel data analysis was estimated with a two-way random effect model, it is seen that the results obtained in both models are positive and statistically significant. That is, volatility increases by $0.01 \%$ when the case increase rate increases by $1 \%$, while it increases by $0.04 \%$ when the death rate increases by $1 \%$.

In this study, the effect of the early period COVID-19 Pandemic deaths and the number of cases in 15 European countries and Turkey on the volatility in the European stock markets were examined by panel data analysis method using daily data for the period 17.02.2020 - 24.04.2020. As a result of the analysis made with the LLC panel unit root test, it was seen that the series were stationary at the level. In this case, the models were estimated with the panel LSM. According to the results of the analysis, the effect of the number of the cases and death rates on volatility is positive and statistically significant. This result is consistent with Erdem (2020), Albulescu (2021) and Uddin et al. (2021). Based on the results obtained in this study; in order not to affect the financial markets more deeply in Turkey and European countries, the COVID-19 pandemic and similar crises should be detected early. It is very important to take timely measures to ensure the sustainability of the economy, business, and social life, while effectively combating this and similar epidemics. 